\section{Comparison of $\gamma$-aminobutyric acid and biogenic amine content of different types of ewe's milk cheese produced in Sardinia, Italy}

\author{
Gavina Manca, ${ }^{1}$ Arianna Porcu, ${ }^{1}$ \\ Antonio Ru, ${ }^{1}$ Margherita Salaris, ${ }^{1}$ \\ Mario A. Franco, ${ }^{1}$ Enrico P.L. De Santis ${ }^{2}$ \\ ${ }^{1}$ Laboratory of Commodity Science \\ Technology and Quality, Department of \\ Economic and Business Sciences, \\ University of Sassari; ${ }^{2}$ Department of \\ Veterinary Medicine, University of \\ Sassari, Italy
}

\section{Abstract}

The bioactive compounds $\gamma$-aminobutyric acid (GABA) and biogenic amines (BA), together with protein-free amino acids, were measured by high-performance liquid chromatography in ewe's milk cheeses produced in Sardinia with different technological traits. The study included three types of cheese: Pecorino Sardo PD0, Pecorino and Casu Marzu. Farmhouse Casu Marzu and Pecorino showed GABA content (maximum levels:

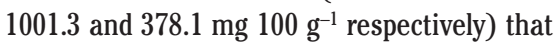
had never been found so high in cheese before, suggesting that these types of cheese present ideal conditions to produce GABA. These two types of cheese also showed high levels of BA (their total maximum levels were 1035.7 and $288.0 \mathrm{mg}^{100 \mathrm{~g}^{-1}}$ respectively). Pearson correlation analysis detected significant correlation between GABA and the main BA present in the cheeses (tyramine, cadaverine and putrescine), suggesting that the factors affecting the production of GABA are the same as those influencing BA formation.

\section{Introduction}

Consumers' interest in the relationship between diet and health has increased the demand for information about the specific health characteristics of food. It is well known that food can contain ingredients that may have physiological benefits and/or reduce the risk of chronic disease, or even represent significant risk factors influencing ill health. In cheese, compounds like amino acids are freed during proteolysis; they are substrates for secondary catabolic reactions by means of bacteria with aminoacyl decarboxylase activity that may yield bioactive compounds. Some of them present useful nutraceutical properties, such as $\gamma$-aminobutyric acid (GABA), while others, such as biogenic amines (BA), may have negative effects on human health.

Over the last decade attention has been paid to the presence of GABA in cheese and dairy product, as a result of its health-related benefits (Mills et al., 2009; Wang et al., 2010; Nejati et al., 2013). GABA is a non-protein amino acid acting as one of the main inhibitory neurotransmitters in the sympathetic mammalian nervous system and exerts positive effects in the treatment of sleeplessness, depression, chronic alcoholrelated symptoms (Oh et al., 2003) and Parkinson's disease (De Jong et al., 1984). In addition, it has shown antitumorigenic activity (Thaker et al., 2005) and, since it is a strong secregatogue of insulin from the pancreas, it can prevent diabetes (Hagiwara et al., 2004).

GABA is produced by the decarboxylation of glutamate catalysed by the enzyme L-glutamic acid decarboxylase (GAD). This enzyme is present in different species of microorganism that could be used for the development of probiotic cheese (Wang et al., 2010). The most interesting are the lactic acid bacteria (LAB), in particular several strains of Lactobacillus brevis (Mills et al., 2009), Lactobacillus plantarum, Lactobacillus delbrueckii subsp. bulgaricus, Lactobacillus casei and Lactococcus lactis subsp. Lactis (Siragusa et al., 2007; Mills et al., 2009; Wang et al., 2010). The Enterococcus spp. and Streptococcus spp. also include strains that have shown GAD activity (Hayakawa et al., 1997).

Other research has shown that these species of bacteria are also involved in the production of BA (Galgano et al., 2001; Linares et al., 2012; Lorencová et al., 2012), considered as a serious health problem when present at significant levels (Stratton et al., 1991). Tyramine, $\beta$-phenylethylamine, histamine, tryptamine, cadaverine, putrescine, spermine and spermidine are considered as the most important amines occurring in cheese.

In cheese, BA are considered as an indicator of poor hygienic conditions of raw material and/or manufacturing practices since their production and accumulation is often associated with the activity of contaminant bacteria (Loizzo et al., 2013). In general, artisanal sheep cheeses are rich in GABA (Siragusa et al., 2007) but also in BA (Loizzo et al., 2013; Mascaro et al., 2010). In fact, microbial decarboxylase activity requires the availability of free amino acid precursors, produced as an outcome of proteolysis, and favourable $\mathrm{pH}$ and temperature conditions that can be achieved during ripening (Siragusa et al., 2007; Linares et al., 2012; Dhakal et al., 2012). Some research has reported that GABA is also present in Pecorino Sardo (Siragusa et al., 2007), as are BA (Manca et al., 2000), even if these studies were limited to a very few samples. For these reasons this study has concerned the
Correspondence: Gavina Manca, Laboratory of Commodity Science Technology and Quality, Department of Economic and Business Sciences, University of Sassari, via Muroni 25, 07100 Sassari, Italy.

Tel: +39.079 .229579 - Fax +39.079 .229579 .

E-mail: gmanca@uniss.it

Key words: GABA; Biogenic amines; Ewe's milk cheese; Pecorino; Casu Marzu.

Conflict of interest: the authors declare no potential conflict of interest.

Received for publication: 8 September 2014. Revision received: 12 March 2015.

Accepted for publication: 17 March 2015.

This work is licensed under a Creative Commons Attribution 3.0 License (by-nc 3.0).

(C) Copyright G. Manca et al., 2015

Licensee PAGEPress, Italy

Italian Journal of Food Safety 2015; 4:4700

doi:10.4081/ijfs.2015.4700

simultaneous determination of GABA and BA in Pecorino Sardo produced in cheese factories, Pecorino produced in farmhouses, and Casu Marzu, made from insect larvae (Piophila casei), in order to assess the variability of these nitrogenous compounds important to define cheese quality, in products obtained with different technological traits.

\section{Materials and Methods}

The study was carried out on traditional cheeses made in Sardinia (Italy) from whole ewe's milk. Samples were collected at different dairies and at different stages of ripening. The types of cheese considered were Pecorino Sardo protected designation of origin (PDO), produced at cheese factories (13 samples with ripening time ranging from $30-360$ days), farmhouse Pecorino (12 samples with ripening time ranging from 60-360 days), and farmhouse Casu Marzu (9 samples with ripening time ranging from 60-90 days). Pecorino Sardo PD0 produced in cheese factories is a semi-cooked cheese made from thermised milk inoculated with a starter culture and coagulated with calf rennet. Ripening takes place in ripening rooms, the temperature (between $6-12^{\circ} \mathrm{C}$ ) and relative humidity (between $80-95 \%$ ) of which are measured and controlled automatically.

Pecorino cheese obtained from farmhouses is a semi-cooked cheese made from raw milk without a starter culture and coagulated with calf rennet. Ripening takes place in rooms with no control over humidity or temperature, which may even reach room values. 
Casu Marzu (also called casu modde, casu cundídu, or casu fràzigu in Sardinian language, which translates rotten cheese) is a Sardinian cheese produced with the use of larvae of the cheese fly Piophila casei. It is prepared in summer, when higher temperatures favour the life-cycle of the fly, and derived from Pecorino cheese that producers place in the warmer rooms of the plant, uncovered, so that flies have better access to lay their eggs in it. After 60-90 days of ripening the cheese is ready to eat.

To extract the nitrogenous compounds considered, an amount of $1 \mathrm{~g}$ of ground cheese was weighed directly in a centrifuge tube and $20 \mathrm{~mL}$ of $\mathrm{HCl} 0.1 \mathrm{M}$ added. The mixture was then homogenised in an ULTRA TURRAX homogeniser (Zipperer, Staufen, Germany) for 5 min. The cheese slurry obtained was centrifuged (ALC PK131R; ALC International S.r.l., Milan, Italy) at $7100 \mathrm{x}$ g for $20 \mathrm{~min}$ at $4^{\circ} \mathrm{C}$. The supernatant was recovered and the residue reextracted using the same procedure. The two acid extracts were combined and diluted to 50 $\mathrm{mL}$ with $\mathrm{HCl} 0.1 \mathrm{M}$. One mL of the extracts was diluted to $10 \mathrm{~mL}$ with $\mathrm{HCl} 0.1 \mathrm{M}$ and then an aliquot of $400 \mu \mathrm{L}$ was derivatised with Dns-Cl.

To prepare dansyl derivatives of free amino acids (FAA) and BA, the method described by Vinci and Antonelli (2002), was followed, with some modifications. $40 \mathrm{~L}$ of saturated sodium carbonate solution at $20^{\circ} \mathrm{C}, 200 \mathrm{~L}$ of dansyl chloride solution (1.5\% w/v in acetone) and $300 \mathrm{~L}$ of acetonitrile were added to $400 \mathrm{~L}$ of standard solutions or sample extracts. The vial containing the reaction mixture was capped, vortexed and then incubated at $60^{\circ} \mathrm{C}$ for 30 min under stirring in a SH 2000-DX Thermo mixer (Finepcr, Seoul, Korea). In order to eliminate the excess of dansyl chloride the mixture was treated with $50 \mathrm{~L}$ of L-asparagine solution $(2.2 \% \mathrm{w} / \mathrm{v}$ in water), then $10 \mathrm{~L}$ of glacial acetic acid was added to remove the excess of carbonate. The solution was filtered through a $0.22 \mathrm{~m}$ PVDF syringe filter (Millipore, Bedford, MA, USA) then $10 \mathrm{~L}$ were injected in high-performance liquid chromatography.

Simultaneous separation of dansyl derivatives of GABA, protein FAA and BA was performed in a Varian (Walnut Creek, CA, USA) chromatography system equipped with a ProStar 230 Solvent Delivery System, a ProStar 410 autosampler, and an LC 305 fluorescent detector (Linear Instruments, Reno, NV, USA). The system was controlled by Varian Star Chromatography Workstation software (Version 4.5). The column used was an Alltima $\mathrm{C}_{18}$ column, $150 \mathrm{~mm}$ x $4.6 \mathrm{~mm}, 3 \mathrm{~m}$ [Alltech Italia, Sedriano (MI), Italy], fitted with an Alltima $\mathrm{C}_{18}$ guard column, $7.5 \mathrm{~mm}$ x $4.6 \mathrm{~mm} \times 5$ $\mathrm{m}$, thermostated at $40^{\circ} \mathrm{C}$. Detection was carried out with the fluorescent detector operating at 340 and $520 \mathrm{~nm}$ as excitation and emission wavelengths respectively.
Free amino acids and BA were determined by the liquid chromatographic method described by Minocha and Long (2004). The solvents used for separation were eluent A: $100 \%$ acetonitrile (ACN) and eluent B: $20 \mathrm{mM}$ ammonium acetate buffer ( $\mathrm{pH}$ 5.9) containing $3 \% \mathrm{v} / \mathrm{v} 2$-propanol. A gradient programme was implemented as follows: time $=0, \mathrm{~A}: \mathrm{B}(10: 90)$, flow=0.5 mL min ${ }^{-1}$; time $=1 \mathrm{~min}, \mathrm{~A}: B(10: 90)$, flow $=0.5 \mathrm{~mL} \mathrm{~min}^{-1}$; time $=50 \mathrm{~min}, \mathrm{~A}: \mathrm{B}(65: 35)$, flow $=0.5 \mathrm{~mL} \mathrm{~min}^{-1}$; time $=65 \mathrm{~min}, \mathrm{~A}: \mathrm{B}(100: 0)$, flow=0.5 mL min ${ }^{-1}$; time $=66 \mathrm{~min}, \mathrm{~A}: B(100: 0)$, flow $=2 \mathrm{~mL} \mathrm{~min}^{-1}$; time $=70 \mathrm{~min}, \mathrm{~A}: \mathrm{B}(10: 90)$, flow $=0.5 \mathrm{~mL} \mathrm{~min}^{-1}$. An equilibration time of 10 min was applied to achieve mobile phase stabilisation.

The identification of the nitrogenous compounds was performed by comparison of the retention times of peaks in the samples to those of standard solutions and by addition of the suspected compound to the samples. A calibration curve was obtained by analysing standard solutions at 9 different concentrations and calibration graphs were constructed by plotting the peak area versus each analyte concentrations. Quantification was accomplished by direct interpolation in the standard curves for each compound.

\section{Statistical analysis}

Statistical analyses of the data were performed using the software package SPSS 14 (SPSS Inc., Chicago, IL, USA). The results were expressed as means of two replications.
Pearson correlation analysis was conducted to determine the relationship between the different compounds considered. Statistical significance was declared at $\mathrm{P}=0.01$.

\section{Results and Discussion}

On the basis of the original method designed for the analysis of FAA and polyamines (Minocha and Long, 2004), we developed a method that allowed extending the analysis to other seven BA. To do this, it was necessary to extend the chromatographic running time from 56 to $70 \mathrm{~min}$. In Figure 1 the chromatograms of a cheese sample and of a standard solution of amino acids and amines are shown. Dansyl amino acids and dansyl BA were eluited in the following order: aspartic acid, glutamic acid, serine, threonine, glycine, alanine, arginine, proline, $\gamma$-amino butyric acid, valine, methionine, isoleucine, leucine, phenylalanine, ornithine, cysteine+cystine, lysine, histidine, tyrosine, agmatine, tryptamine, phenylethylamine, putrescine, cadaverine, hystamine, serotonin, tiramine, spermidine and spermine.

The content of the compounds analysed in the three types of ewe's milk cheese considered are shown in Table 1. The highest level of GABA was found in Casu Marzu (ranging from 34.4 to $1001.3 \mathrm{mg} 100 \mathrm{~g}^{-1}$ ) and in Pecorino
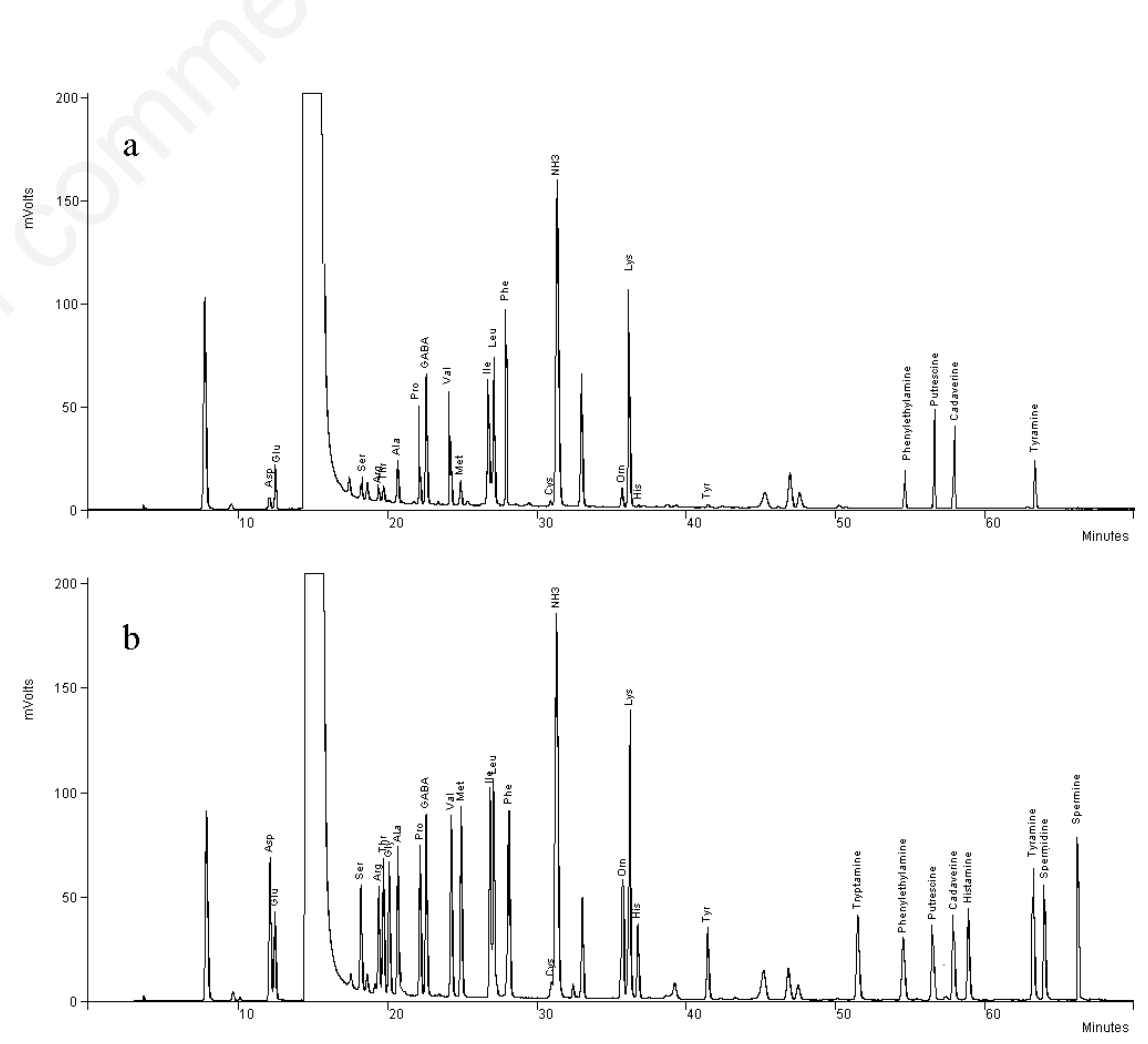

Figure 1. Chromatogram of a cheese sample (a) and of a standard solution of amino acids and amines (b). 
(ranging from 0.0 to $378.1 \mathrm{mg} 100 \mathrm{~g}^{-1}$ ), while the samples of Pecorino Sardo PDO showed a lower content (ranging from 2.3 to $52.0 \mathrm{mg}$ $\left.100 \mathrm{~g}^{-1}\right)$. The results showed great variability in GABA content not only between the three types of cheese but also within the same type. By comparing these Sardinian products with other ewe's milk cheeses it was noted that in most of the samples of both Casu Marzu and Pecorino the GABA content was from 2 to 10 times higher than the maximum level (39.1 $\mathrm{mg} 100 \mathrm{~g}^{-1}$ ) measured in other types of Italian cheese (Siragusa et al., 2007). In particular, three samples of Casu Marzu had a content that was as much as 20 times greater than that reported in the above-mentioned work. The differences in GABA content appear to be dependent on the different degree of proteolysis observed between the three types of cheese. In fact, considering the content of total FAA as an index of proteolysis level, calculated as the sum of the individual FAA measured, a significant correlation with GABA was found (Pearson coefficient 0.555 at $\mathrm{P}=0.01$ ). As for
GABA, the higher levels of Total FAA were found in the samples of Casu Marzu. This is most probably due to the high proteolytic activity induced by the Piophila casei larvae, and to the high temperature used for cheese storage (Mazzette et al., 2010). The farmhouse samples of Pecorino tended to have a Total FAA content greater than those of Pecorino Sardo PD0 from cheese factories. As reported in the literature, such differences can be attributed to changes in manufacturing processes (Pintado et al., 2008; Schirone et al., 2011). By comparison, in cheese samples with the same age, great variability in Total FAA content was also found within the same type of cheese, highlighting that production processes can vary from one cheesemaker to another. In Pecorino Sardo, as observed in a previous work (Manca et al., 1999), variability in the FAA content was due to a production protocol that allowed the use of different technological features. Considering the amino acid profile (percentage of the Total FAA for each amino acid) shown in Table 2, it is possible to highlight that in three samples of Pecorino and in three of Casu Marzu, GABA is the amino acid present in the highest percentage with respect to the Total FAA (from 12.3 to 18.5 and from 14.2 to $22.9 \%$ respectively). In almost all the other samples, including the factory products, glutamic acid, the precursor of GABA, is the amino acid mostly represented, followed by leucine, valine and lysine. This FAA profile is similar to that found in other ewe's milk cheese (Izco et al., 2000; Barcina et al., 1995), while to our knowledge, GABA has never been found as the major FAA in sheep's cheese.

As for GABA and Total FAA, great variability in the total content of BA was found between the different types of cheese, but also within the same type. Casu Marzu showed the highest content of Total BA; in particular, two samples presented values of 1035.7 and $923.0 \mathrm{mg} 100 \mathrm{~g}^{-1}$ respectively. The other Casu Marzu samples had values ranging from 62.9 to $282.1 \mathrm{mg} 100$ $\mathrm{g}^{-1}$ for this parameter, more similar to that found in other artisanal Italian cheeses, such as Formaggio di Fossa (Mascaro et al., 2010)

Table 1. Content of $\gamma$-aminobutyric acid, total free amino acids, and biogenic amines in different types of ewe's milk cheese produced in Sardinia ( $\left.\mathrm{mg} 100 \mathrm{~g}^{-1}\right)$.

\begin{tabular}{|c|c|c|c|c|c|c|c|c|c|c|c|c|}
\hline Types of cheese R & $\begin{array}{l}\text { ning time } \\
\text { (days) }\end{array}$ & GABA & $\begin{array}{l}\text { Total } \\
\text { FAA }\end{array}$ & Triptamine & $\begin{array}{l}\beta \text {-phenyl- } \\
\text { ethylamine }\end{array}$ & Putrescine & adaverine & Histamine & yramine & vermidine & Spermine & $\begin{array}{c}\text { Total } \\
\text { BA }\end{array}$ \\
\hline \multirow[t]{13}{*}{ Pecorino Sardo PDO } & 30 & 2.5 & 281.3 & 1.6 & nd & 0.1 & 1.3 & nd & 1.6 & 1.0 & 0.9 & 6.5 \\
\hline & 30 & 2.3 & 334.7 & nd & nd & 0.1 & 1.4 & 0.8 & 3.5 & nd & 4.0 & 9.8 \\
\hline & 60 & 4.5 & 822.9 & 9.3 & nd & 1.1 & 1.4 & nd & 19.3 & 0.6 & 1.8 & 33.5 \\
\hline & 60 & 3.7 & 815.0 & 5.7 & nd & 0.1 & 1.4 & 0.5 & 3.5 & 2.9 & 0.4 & 14.4 \\
\hline & 60 & 4.2 & 768.7 & 2.1 & nd & 0.1 & 9.7 & 7.2 & 3.5 & 1.1 & 0.4 & 24.2 \\
\hline & 60 & 3.6 & 794.6 & 1.4 & nd & 1.1 & 1.7 & 0.7 & lnd & nd & 5.4 & 20.2 \\
\hline & 90 & 8.8 & 1473.0 & 2.4 & nd & 0.7 & 0.9 & 2.7 & 4.4 & 7.2 & 1.0 & 19.2 \\
\hline & 150 & 2.7 & 1615.6 & 3.2 & nd & 0.1 & 3.6 & 2.1 & 7.9 & 3.4 & 1.0 & 21.3 \\
\hline & 150 & 13.7 & 578.7 & nd & nd & nd & 0.1 & nd & 1.4 & 2.7 & 0.2 & 4.4 \\
\hline & 180 & 2.8 & 588.1 & 1.7 & nd & 0.5 & 0.3 & 3.3 & 1.0 & 0.4 & 0.3 & 7.4 \\
\hline & 180 & 6.1 & 934.4 & nd & nd & 0.1 & 1.3 & 0.6 & 0.4 & 0.6 & 0.2 & 3.1 \\
\hline & 270 & 52.0 & 1387.0 & nd & nd & nd & 0.7 & 4.3 & 6.4 & 11.1 & 1.2 & 23.6 \\
\hline & 360 & 10.2 & 1893.2 & nd & nd & 0.8 & 2.6 & 5.3 & 16.3 & 0.5 & 2.4 & 27.8 \\
\hline \multirow[t]{12}{*}{ Pecorino } & 60 & 71.3 & 619.3 & nd & 0.9 & 3.4 & 15.4 & nd & 5.7 & nd & nd & 25.5 \\
\hline & 60 & 20.6 & 840.8 & 2.9 & 2.1 & 1.1 & 5.3 & nd & 4.7 & nd & nd & 16.1 \\
\hline & 90 & 228.4 & 1438.3 & nd & nd & 2.7 & 11.0 & nd & 30.8 & nd & nd & 44.5 \\
\hline & 90 & 378.1 & 2046.7 & 4.1 & 8.6 & 92.7 & 137.0 & 24.4 & 21.0 & nd & nd & 287.8 \\
\hline & 150 & nd & 1242.4 & nd & nd & nd & nd & nd & 13.2 & nd & nd & 13.2 \\
\hline & 150 & 11.6 & 1480.5 & nd & nd & 16.4 & 5.5 & nd & 37.3 & nd & nd & 59.2 \\
\hline & 180 & 20.5 & 3266.5 & nd & 5.4 & nd & 4.8 & nd & 68.6 & nd & nd & 73.4 \\
\hline & 180 & 135.4 & 5401.8 & 11.1 & 4.7 & 13.0 & 1.7 & 128.4 & 93.0 & nd & nd & 247.2 \\
\hline & 180 & 9.8 & 411.1 & nd & nd & nd & 21.3 & 19.5 & 1.6 & nd & nd & 42.4 \\
\hline & 270 & 133.3 & 1973.9 & nd & nd & nd & 5.2 & nd & 4.2 & nd & nd & 9.4 \\
\hline & 360 & 339.0 & 2754.4 & 5.4 & 3.0 & 33.6 & 33.2 & 33.4 & 17.8 & nd & nd & 126.4 \\
\hline & 360 & 75.3 & 5268.9 & 13.5 & 7.1 & 5.1 & 33.6 & nd & 19.7 & nd & nd & 79.0 \\
\hline \multirow[t]{9}{*}{ Casu Marzu } & 60 & 51.3 & 2393.4 & nd & 4.9 & 4.1 & 28.8 & nd & 3nd & nd & nd & 62.9 \\
\hline & 60 & 203.5 & 1946.6 & 5.1 & nd & 1.9 & 3.1 & nd & 61.0 & nd & nd & 71. \\
\hline & 90 & 122.5 & 4019.7 & nd & 10.8 & 67.8 & 8.8 & nd & 150.1 & nd & nd & 226 \\
\hline & 90 & 63.2 & 4344.5 & 16.0 & 16.2 & 90.6 & 8.0 & nd & 167.5 & nd & nd & 282 \\
\hline & 90 & 1001.3 & 7051.6 & 15.8 & 13.2 & 58.2 & 69.6 & nd & 93.7 & nd & nd & 237 \\
\hline & 90 & 66.4 & 6319.9 & 12.0 & 10.8 & 39.1 & 6.3 & nd & 187.3 & nd & nd & 244 \\
\hline & 90 & 959.8 & 4196.8 & 33.2 & 90.9 & 140.3 & 462.0 & 99.3 & 188.2 & nd & nd & 923.0 \\
\hline & 90 & 34.4 & 2535.8 & nd & nd & 8.3 & 24.7 & 35.6 & 47.1 & nd & nd & 115 \\
\hline & 90 & 806.2 & 3705.5 & 41.8 & nd & 165.8 & 470.7 & 126 & 231.4 & nd & nd & \\
\hline
\end{tabular}

GABA, $\gamma$-aminobutyric acid; FAA, free amino acids; BA, biogenic amine; PDO; protected designation of origin; nd, not detected. 
and Pecorino di Farindola (Schirone et al., 2011). Considering that threshold values of 75$90 \mathrm{mg} 100 \mathrm{~g}^{-1}$ have been proposed for Total BA in food (Spanjer and Van Roode, 1991; ten Brink et al., 1990), Casu Marzu can be considered unsafe, especially for patients treated with monoamine oxidase inhibitor drugs (MA0Is). Also four samples of Pecorino showed a Total BA content (between 79.0 and

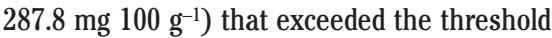
proposed, while the other samples presented values ranging from 9.4 and $73.4 \mathrm{mg} 100 \mathrm{~g}^{-1}$ that did not represent a risk for consumers' health. However, the samples of Pecorino had, in general, a higher level of Total BA than those of Pecorino Sardo PDO, whose values varied from 3.1 to $33.5 \mathrm{mg} 100 \mathrm{~g}^{-1}$. Seeing that BA are considered an index of poor hygienic conditions, the high content of these compounds measured in Casu Marzu and Pecorino could be related to less than optimal environmental conditions during the production process (Mazzette et al., 2010). The use of insects, as in Casu Marzu, and of raw milk, combined with a high storage temperature, seems to favour the production of BA, as already shown in other artisanal sheep's cheeses (Loizzo et al., 2013; Mascaro et al., 2010). On the contrary, in Pecorino Sardo PDO, where the milk used is thermised and the temperature and humidity conditions under control, the products showed a low content of total BA. The variability observed in BA content, as observed by Novella-Rodriguez et al. (2003) and Pintado et al. (2008) in other types of cheeses, could be attributable to differences in the manufacturing process. A positive correlation was found between total BA and total FAA (Pearson coefficient $=0.513$ at $\mathrm{P}=0.01$ ), confirming the findings of Giraffa et al. (1995) who observed an increase in BA corresponding to an increase in proteolysis. Tyramine, cadaverine and putrescine were the main amines in all the types of cheese considered, even if their content varied to a great extent: in this respect the statements made previously are valid for the total content of BA. In Casu Marzu the highest levels found for tyramine, cadaverine and putrescine were $231.4,470.7$ and $165.8 \mathrm{mg}$ $100 \mathrm{~g}^{-1}$ respectively. Therefore, by comparison with the literature (Loizzo et al., 2013; Schirone et al., 2013), some samples of Casu Marzu seem to present the highest contents found in cheeses up to now. In blue cheese -

Table 2. Free amino acid profile of the different types of ewe's milk cheese produced in Sardinia (percentage of the total free amino acids for each amino acid).

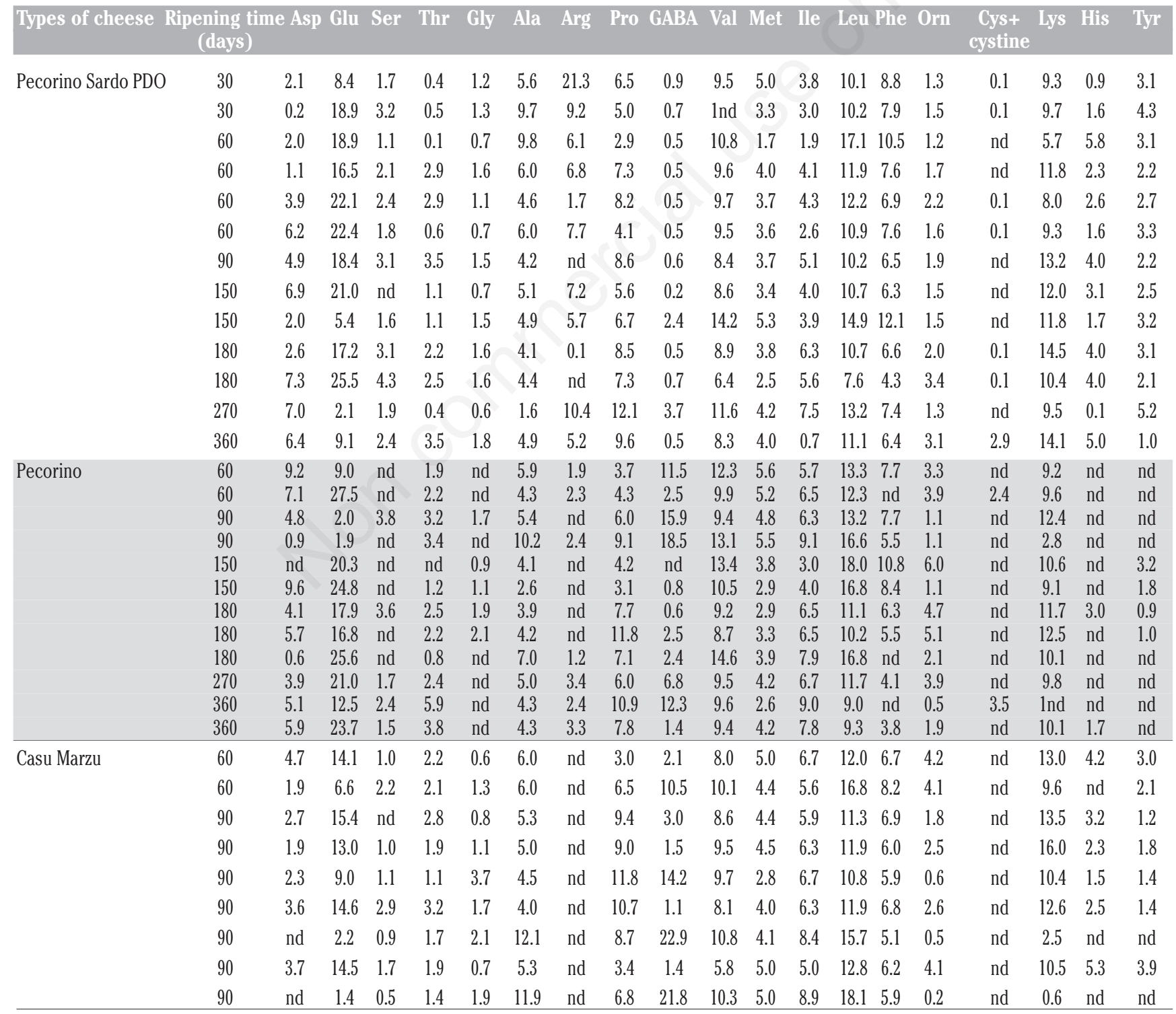

Asp, aspartic acid; Glu, glutamic acid; Ser, serine; Thr, threonine; Gly, glycine; Ala, alanine; Arg, arginine; Pro, proline; GABA, $\gamma$-aminobutyric acid; Val, valine; Met, methionine; Ile, isoleucine; Leu, leucine; Phe, phenylalanine; Orn, ornithine; Cys + Cys, cysteine; Lys, lysine; His, histidine; Tyr, tyrosine. PDO, protected designation of origin; nd, not detected. 
Table 3. Pearson correlation coefficients among the variables $\gamma$-aminobutyric acid, total free amino acids and biogenic amines measured in different types of ewe's milk cheese produced in Sardinia.

\begin{tabular}{|c|c|c|c|c|c|c|c|c|c|c|c|}
\hline & GABA & Triptamine & Putrescine & Cadaverine & Histamine & Tiramine & Spermidine & Spermine & $\begin{array}{l}\beta \text {-phenyl- } \\
\text { ethylamine }\end{array}$ & TOT FAA & TOT BA \\
\hline GABA & 1 & $0.763^{* *}$ & $0.779 * *$ & $0.795^{* *}$ & $0.557^{* *}$ & $0.595^{* *}$ & -0.182 & -0.225 & $0.610^{* *}$ & $0.555^{* *}$ & $0.794 * *$ \\
\hline Triptamine & $0.763^{* *}$ & 1 & $0.837^{* *}$ & $0.859 * *$ & $0.706^{* *}$ & $0.780^{* *}$ & -0.185 & -0.140 & $0.572^{* *}$ & $0.568^{* *}$ & $0.513^{* *}$ \\
\hline Putrescine & $0.779 * *$ & $0.837^{* *}$ & 1 & $0.857^{* *}$ & $0.616^{* *}$ & $0.824^{* *}$ & -0.207 & -0.229 & $0.603^{* *}$ & $0.519 * *$ & $0.917^{* *}$ \\
\hline Cadaverine & $0.795^{* *}$ & $0.859 * *$ & $0.857^{* *}$ & 1 & $0.728 * *$ & $0.638^{* *}$ & -0.142 & -0.156 & $0.651^{* *}$ & 0.301 & $0.938 * *$ \\
\hline Histamine & $0.557^{* *}$ & $0.706^{* *}$ & $0.616^{* *}$ & $0.728 * *$ & 1 & $0.553^{* *}$ & -0.141 & -0.162 & $0.413^{*}$ & $0.367^{*}$ & $0.947^{* *}$ \\
\hline Tiramine & $0.595^{* *}$ & $0.780 * *$ & $0.824^{* *}$ & $0.638^{* *}$ & $0.553^{* *}$ & 1 & -0.236 & -0.282 & $0.533^{* *}$ & $0.731^{* *}$ & $0.783^{* *}$ \\
\hline Spermidine & -0.182 & -0.185 & -0.207 & -0.142 & -0.141 & -0.236 & 1 & 0.094 & -0.134 & -0.252 & $0.836^{* *}$ \\
\hline Spermine & -0.225 & -0.140 & -0.229 & -0.156 & -0.162 & -0.282 & 0.094 & 1 & -0.149 & -0.260 & -0.189 \\
\hline$\beta$-phenyl-ethylamine & $0.610^{* *}$ & $0.572^{* *}$ & $0.603^{* *}$ & $0.651^{* *}$ & $0.413^{*}$ & $0.533^{* *}$ & -0.134 & -0.149 & 1 & $0.402^{*}$ & -0.217 \\
\hline Total FAA & $0.555^{* *}$ & $0.568^{* *}$ & $0.519 * *$ & 0.301 & $0.367^{*}$ & $0.731^{* *}$ & -0.252 & -0.260 & $0.402 *$ & 1 & $0.648^{* *}$ \\
\hline Total BA & $0.794^{* *}$ & $0.917^{* *}$ & $0.938 * *$ & $0.947^{* *}$ & $0.783^{* *}$ & $0.836^{* *}$ & -0.189 & -0.217 & -0.217 & $0.513^{* *}$ & 1 \\
\hline
\end{tabular}

GABA, $\gamma$-aminobutyric acid; FAA, free amino acids; BA, biogenic amine. ${ }^{*}$ Correlation is significant at the $\mathrm{P}<0.05 ;{ }^{* *}$ correlation is significant at $\mathrm{P}<0.01$.

one of the richest in BA (Loizzo et al., 2013; Novella-Rodriguez et al., 2003) - the highest levels of tyramine, cadaverine and putrescine were $158.5,210.4$ and $25.7 \mathrm{mg} 100 \mathrm{~g}^{-1}$ respectively. Regardless of the type of cheese, histamine, triptamine and $\beta$-phenylethylamine were present in only about $50 \%$ of the samples and also for these amines the highest concentrations were found in samples of Casu Marzu and Pecorino. The polyamines spermidine and spermine were present only in Pecorino Sardo PD0, with a level ranging from 0.0 to 11.1 and from 0.0 to $5.4 \mathrm{mg} 100 \mathrm{~g}^{-1}$ respectively, similar to that found in blue cheese (NovellaRodriguez et al., 2003). Among the amines determined, agmatine and serotonin were never found. This is in accordance with previous works in which these amines are usually present at low levels or are not detected in cheese (Loizzo et al., 2013; Custodio et al., 2007; Novella-Rodriguez et al., 2003).

\section{Relationship between $\gamma$-aminobu- tyric acid and biogenic amines}

The Pearson test showed a significant correlation $(\mathrm{P}=0.01)$ between $\mathrm{GABA}$ and the amines putrescine, cadaverine and triptamine (Pearson correlation coefficients $0.779,0.795$ and 0.763 respectively) (Table 3 ). Therefore, it may be assumed that factors responsible for BA production, such as temperature, $\mathrm{pH}$, availability of FAA and, primarily, microorganisms with amino acid decarboxylase activity (Pinho et al., 2001), may also affect GABA synthesis (Siragusa et al., 2007; Dhakal et al., 2012).

The literature highlights that in cheese and other dairy products some microbial species responsible for the synthesis of one or more BA are also involved in GABA production. In particular, the genera Lactobacilli include several strains of the species $L b$. paracasei, $L b$. delbrueckii, Lb. plantarum, Lb. brevis, and
Lactococcus lactis, active in GABA production (Siragusa et al., 2007) but some of them can form one or more BA (Linares et al., 2012; Galgano et al., 2001); likewise a Streptococcus thermophilus strain can form GABA, tyramine and histamine. Cadaverine, putrescine and histamine (Maifreni et al., 2013), but also GABA could be produced by species belonging to the genera Enterococcus (Dhakal et al., 2012). Many of these species of bacteria, in particular $L b$. brevis, $L b$. plantarum, $\mathrm{Lb}$. delbrueckii, Lb. paracasei, Lactococcus lactis, Streptococcus thermophilus and Enterococus $s p p$, were found as components of the microflora of traditional Pecorino Sardo cheese (Mannu et al., 2002; Madrau et al., 2006). Therefore, the types of sheep's cheese considered seem to present the ideal conditions for favouring the production and accumulation of both GABA and BA.

\section{Conclusions}

Great differences were found for GABA, total FAA and BA content in the three types of cheese considered. Farmhouse Casu Marzu and Pecorino are the types of cheese with a high content of GABA, a compound with beneficial functions, but also of BA, in particular tyramine, cadaverine and putrescine that in high concentrations represent a health hazard for consumers. The Pearson correlation test revealed that variability in the content of GABA and BA was correlated with the total FAA, indicating that their production depends on the intensity of the proteolytic phenomena and thus on environmental and manufacturing factors that affect this biochemical event.

Given the significant correlation highlight- ed by the Pearson test $(\mathrm{P}=0.01)$ between GABA and the most frequently represented $\mathrm{BA}$, it was supposed that the production of all these compounds is affected by the same factors. Furthermore, it was shown that the cheeses considered, in particular those of farmhouse Casu Marzu and Pecorino, presented ideal conditions for developing microorganisms and for their carboxylase activity. Considering the interest of the food industry in functional food, Casu Marzu and Pecorino microflora can potentially be useful to enrich cheese or milkfermented products with GABA, but further studies are needed to assess whether microbial strains are present that are capable of producing a high content of GABA but not of BA and to individuate which technological factors may favour the grows of these bacteria.

\section{References}

Barcina Y, Ibáñez FC, Ordhiez AI, 1995. Evolution of free amino acids during Idiazabal cheese ripening. Food Control 6:161-4.

Custodio FB, Tavares E, Abreu Gloria MB, 2007. Extraction of bioactive amines from grated Parmesan cheese using acid, alkaline and organic solvents. J Food Compos Anal 20:280-8.

Dhakal R, Bajpai VK, Baek K-H, 2012. Production of GABA ( $\gamma$-aminobutyric acid) by microorganisms: a review. Braz J Microb 1230-41.

De Jong PJ, Lakke JP, Teelken AW, 1984. CSF GABA levels in Parkinson's disease. Adv Neurol 40:427-30.

Galgano F, Suzzi G, Favati F, Caruso M, Martuscelli M, Gardini F, Salzano G, 2001. 
Biogenic amines during ripening in "Semicotto Caprino" cheese: role of enterococci. Int J Food Sci Tech 36:153-60.

Giraffa G, Pepe G, Locci F, Neviani E, Carminati D, 1995. Hemolytic activity, production of thermonuclease and biogenic amines by dairy enterococci. Ital J Food Sci 4:341-9.

Hagiwara H, Seki T, Ariga T, 2004. The effect of pre-germinated brown rice intake on blood glucose and PAI-1 levels in streptozotocin induced diabetic rats. Biosci Biotech Bioch 68:444-7.

Hayakawa K, Ueno Y, Kawamura S, Taniguchi R, Oda K, 1997. Production of $\gamma$-aminobutyric acid by lactic acid bacteria. SeibutsuKogaku Kaishi 75:239-44.

Izco J, Torre P, Barcina Y, 2000. Ripening of Ossau-Iraty cheese: determination of free amino acids by RP-HPLC and of total free amino acids by the TNBS method. Food Control 11:7-11.

Linares DM, Del Río B, Ladero V, Martínez N, Fernández M, Martín MC, Alvarez MA, 2012. Factors influencing biogenic amines accumulation in dairy products. $\mathrm{Fr}$ Microbiol 3:1-10.

Loizzo MR, Menichini F, Picci N, Puoci F, Spizzirri UG, Restuccia D, 2013. Technological aspects and analytical determination of biogenic amines in cheese. Trends Food Sci Tech 30:38-55.

Lorencová E, Buňková L, Matoulková D, Dráb V, Pleva P, Kubáň V, Buňka F, 2012. Production of biogenic amines by lactic acid bacteria and bifidobacteria isolated from dairy products and beer. Int $\mathbf{J}$ Food Sci Tech 47:2086-91.

Madrau MA, Mangia NP, Murgia MA, Sanna MG, Garau G, Leccis L, Caredda M, Deiana P, 2006. Employment of autochthonous microflora in Pecorino Sardo cheese manufacturing and evolution of physicochemical parameters during ripening. Int Dairy $\mathrm{J}$ 16:876-85.

Maifreni M, Frigo F, Bartolomeoli I, Innocente N, Biasutti M, Marino M, 2013. Identification of the Enterobacteriaceae in Montasio cheese and assessment of their amino acid decarboxylase activity. J Dairy Res 80:122-7.

Manca G, Franco MA, Del Caro A, Coloru GC, 1999. The role of the free amino acids profile in characterizing "Pecorino Sardo" cheese. J Commodity Sci 38:167-79.
Manca G, Franco MA, Sanna G, Molinu MG, 2000. Determinazione mediante HPLC del contenuto di ammine biogene in prodotti lattiero-caseari della Sardegna. In: Proc. of 19th National Congress Merceology. Poddighe eds., Sassari, Italy, pp 185-95.

Mannu L, Riu G, Comunian R, Fozzi MC, Scintu MF, 2002. A preliminary study of lactic acid bacteria in whey starter culture and industrial Pecorino Sardo ewe's cheese: PCR-identification and evolution during ripening. Int Dairy Jl 12:17-26.

Mascaro N, Stocchi R, Ricciutelli M, Cammertoni N, Renzi F, Cecchini S, Loschi AR, Rea S, 2010. Contenuto di amine biogene e caratteristiche chimico-fisiche del formaggio di Fossa. Rivista dell'Associazione Italiana dei Veterinari Igienisti A.I.V.I. 8:49-53.

Mazzette R, Colleo MM, Riu GI, Piras G, Piras F, Addis M, Pes M, Pirisi A, Meloni D, Mureddu, A, Spada S, Fiori M, Coinu M, Lentini A, 2010. Produzione di "Casu Marzu" in condizioni controllate: valutazione dell'effetto della colonizzazione da Piophila casei sulle caratteristiche microbiologiche e chimiche dei formaggi. Rivista dell'Associazione Italiana dei Veterinari Igienisti A.I.V.I. 7:45-54.

Mills S, Stanton C, Ross RP, 2009. Microbial production of bioactives: from fermented functional foods to probiotic mechanisms. Austral J Dairy Tech 64:41-9.

Minocha R, Long S, 2004. Simultaneous separation and quantitation of amino acids and polyamines of forest tree tissues and cell cultures within a single high-performance liquid chromatography run using dansyl derivatization. J Chromatogr A 1035:63-73.

Nejati F, Rizzello CG, Di Cagno R, SheikhZeinoddin M, Diviccaro A, Minervini F, Gobbetti M, 2013. Manufacture of a functional fermented milk enriched of Angiotensin-I Converting Enzyme (ACE)inhibitory peptides and $\gamma$-amino butyric acid (GABA). Food Sci Technol 51:183-9.

Novella-Rodriguez S, Veciana-Nogués MT, Izquierdo-Pulido M, Vidal-Carou MC, 2003. Distribution of biogenic amines and polyamines in cheese. J Food Sci 68:750-5.

Oh SH, Soh JR, Cha YS, 2003. Germinated brown rice extract shows a nutraceutical effect in the recovery of chronic alcoholrelated symptoms. J Med Food 6:115-21.
Pinho 0, Ferreira IMPLVO, Mendes E, Oliveira BM, Ferreira M, 2001. Effect of temperature on evolution of free amino acid and biogenic amine contents during storage of Azeitão cheese. Food Chem 287-91.

Pintado AIE, Pinho 0, Ferreira IMPLVO, Pintado MME, Gomes AMP, Malcata FX, 2008. Microbiological, biochemical and biogenic amine profiles of Terrincho cheese manufactured in several dairy farms. Int Dairy J 18:631-40.

Schirone M, Tofalo R, Mazzone G, Corsetti A, Suzzi G, 2011. Biogenic amine content and microbiological profile of Pecorino di Farindola cheese. Food Microbiol 28:12836.

Schirone M, Tofalo R, Fasoli G, Perpetuini G, Corsetti A, Manetta AC, Ciarrocchi A, Suzzi G, 2013. High content of biogenic amines in Pecorino cheeses. Food Microbiol 34:137-44.

Siragusa S, De Angelis M, Di Cagno R, Rizzello CG, Coda R, Gobbetti M, 2007. Synthesis of $\gamma$-aminobutyric acid by lactic acid bacteria isolated from a variety of Italian cheeses. Appl Environ Microb 73:7283-90.

Spanjer MC, Van Roode BASW, 1991. Towards a regulatory limit for biogenic amines in fish, cheese and sauerkraut. De Ware(n)Chemicus 21:139-67.

Stratton JE, Hutkins RW, Taylor SL, 1991. Biogenic amines in cheese and other fermented foods: a review. J Food Protect 54:460-70.

ten Brink B, Damink C, Joosten HMLJ, Huis in't Veld JHJ, 1990. Occurrence and formation of biologically active amines in foods. Int J Food Microbiol 11:73-84.

Thaker PH, Yokoi K, Jennings NB, Li Y, Rebhun RB, Rousseau DL, Fan D, Sood AK, 2005. Inhibition of experimental colon cancer metastasis by the GABA-receptor agonist nembutal. Cancer Biol Ther 4:753-8.

Vinci G, Antonelli ML, 2002. Biogenic amines: quality index of freshness in red and white meat. Food Control 13:519-24.

Wang HK, Dong C, Chen YF, Cui LM, Zhang HP, 2010. A new probiotic Cheddar cheese with high ACE-inhibitory activity and $\gamma$ aminobutyric acid content produced with Koumiss-derived Lactobacillus casei Zhang. Food Technol Biotechnol 48:62-70. 